Article

\title{
An Optimized Multilayer Perceptrons Model Using Grey Wolf Optimizer to Predict Mechanical and Microstructural Properties of Friction Stir Processed Aluminum Alloy Reinforced by Nanoparticles
}

\author{
Ahmed B. Khoshaim ${ }^{1}{ }^{\mathbb{D}}$, Essam B. Moustafa ${ }^{1} \mathbb{D}$, Omar Talal Bafakeeh $^{2}$ and Ammar H. Elsheikh ${ }^{3, *(D)}$ \\ 1 Mechanical Engineering Department, Faculty of Engineering, King Abdulaziz University, Jeddah 80204, \\ Saudi Arabia; akhoshaim@kau.edu.sa (A.B.K.); essbahgat@gmail.com (E.B.M.) \\ 2 Industrial Engineering Department, Jazan University, Jazan 45142, Saudi Arabia; albafakeeh@gmail.com \\ 3 Faculty of Engineering, Tanta University, Tanta 31527, Egypt \\ * Correspondence: ammar_elsheikh@f-eng.tanta.edu.eg
}

Citation: Khoshaim, A.B.; Moustafa, E.B.; Bafakeeh, O.T.; Elsheikh, A.H. An Optimized Multilayer Perceptrons Model Using Grey Wolf Optimizer to Predict Mechanical and Microstructural Properties of Friction Stir Processed Aluminum Alloy Reinforced by Nanoparticles. Coatings 2021, 11, 1476. https://doi.org/ 10.3390/coatings11121476

Received: 29 October 2021

Accepted: 26 November 2021

Published: 30 November 2021

Publisher's Note: MDPI stays neutral with regard to jurisdictional claims in published maps and institutional affiliations.

Copyright: (c) 2021 by the authors. Licensee MDPI, Basel, Switzerland. This article is an open access article distributed under the terms and conditions of the Creative Commons Attribution (CC BY) license (https:// creativecommons.org/licenses/by/ $4.0 /)$.

\begin{abstract}
In the current investigation, AA2024 aluminum alloy is reinforced by alumina nanoparticles using a friction stir process (FSP) with multiple passes. The mechanical properties and microstructure observation are conducted experimentally using tensile, microhardness, and microscopy analysis methods. The impacts of the process parameters on the output responses, such as mechanical properties and microstructure grain refinement, were investigated. The effect of multiple FSP passes on the grain refinement, and various mechanical properties are evaluated, then the results are conducted to train a hybrid artificial intelligence predictive model. The model consists of a multilayer perceptrons optimized by a grey wolf optimizer to predict mechanical and microstructural properties of friction stir processed aluminum alloy reinforced by alumina nanoparticles. The inputs of the model were rotational speed, linear processing speed, and number of passes; while the outputs were grain size, aspect ratio, microhardness, and ultimate tensile strength. The prediction accuracy of the developed hybrid model was compared with that of standalone multilayer perceptrons model using different error measures. The developed hybrid model shows a higher accuracy compared with the standalone model.
\end{abstract}

Keywords: friction stir processing; AA2024 aluminum alloy; alumina particles; multilayer perceptrons; grey wolf optimizer

\section{Introduction}

Due to its simplicity, friction stir processing (FSP) has become one of the most important techniques for manufacturing surface composites in recent years. Due to the intense plastic deformation of the FSP process, the mechanical and microstructural properties are enhanced [1-3]. As a result of the unique characteristics of nanocomposite materials, this method has been utilized to fabricate nanocomposite structures for diverse purposes. During dynamic recrystallization of grains, nanocomposite structures contain reinforcement nanoparticles that disperse along grain boundaries [4-10]. $\mathrm{Al}_{2} \mathrm{O}_{3}, \mathrm{SiC}_{2} \mathrm{Ti}_{2} \mathrm{~B}$, and CNT were used as reinforcement particles to strengthen the aluminum alloy matrix; hence, multiple FSP passes are carried out during the process [11-15]. Processing parameters have a considerable influence on FSP and produced metal matrix composites; in particular, the number of processing passes is one such critical parameter that refines grain and improves mechanical properties [16-23]. The dispersion of reinforcing nanoparticles in a metal matrix improves the hardness and wear resistance of manufactured metal matrix nanocomposites (MMNCs) [12,24]. Many studies have studied the impact of $\mathrm{Al}_{2} \mathrm{O}_{3}$ nanoparticles on surface composites, reporting improved mechanical, wear, and strength characteristics, as well as increased or decreased toughness and ductility [25-30]. As a result of these developments, 
the current study evaluated the impacts of processing parameters such as rotational and traverse speeds, and the number of processing passes on the behavior and properties of the manufactured surface composites.

Prediction of the mechanical properties and the microstructure characteristics of the friction stir processed specimens (FSPS) plays a vital role in developing and obtain highquality FSPS with minimum cost. Nevertheless, the nonlinear relationship between the properties of FSPS and the process factors makes this process a cumbersome problem. Most literature studies focused on modeling this process using response surface methodology (RSM) [31-33]. However, RSM has a critical disadvantage as it fits experimental data to a polynomial model with the second-order regardless of the nonlinearity degree of the data. Artificial intelligence-based models such as artificial neural networks (ANN), random vector functional link network (RVFL), and adaptive neuro-fuzzy inference system (ANFIS) have been reported in the literature as a robust prediction tool that used in modeling different nonlinear engineering processes such as friction stir welding process [34-38]. Moreover, the integration between artificial intelligence modeling and metaheuristic optimizers such as equilibrium optimizer [39], Harris hawks optimizer [40], cat swarm optimizer [41], flower pollination [42], crow search optimizer [43], mayfly optimizer [44], ecosystem-based optimizer [45], manta ray foraging optimizer [46], parasitism-predation optimizer [47], and political optimizer [48], has shown promising application in modeling different engineering problems. This artificial based modeling approaches overcomes the problems of conventional mathematical modeling techniques as well as numerical modeling techniques such as model complexity and nonlinearity [49,50]. Kumar et al. [51] developed an ANN model as well as a fuzzy inference model to predict the wear resistance of FSPS made of AA5083 plates. The hardness of the specimens was enhanced by refining the grains using the FSP technique. The input control factors of the model were tool traverse speed, tool rotation speed, and shoulder diameter, while the output response was the wear resistance. The fuzzy model outperformed ANN to predict the wear resistance of FSPS. Rathore et al. [52] predicted the ultimate tensile strength (UTS) and the hardness of Al 2219- $\mathrm{Y}_{2} \mathrm{O}_{3}$ composite processed using FSP technique by utilizing an ANFIS model. The input control variables were spindle rotary speed, traverse speed, tool rotation direction, and number of passes. The results of ANFIS demonstrate its better accuracy and robustness compared with the conventional response surface models. Dinaharan et al. [53] applied an ANN model to predict the tribological properties of FSPS made of copper matrix and ceramic additives such as $\mathrm{Al}_{2} \mathrm{O}_{3}, \mathrm{SiC}, \mathrm{WC}, \mathrm{TiC}$, and $\mathrm{B}_{4} \mathrm{C}$. The input process parameters of the model were ceramic particle, tool rotational speed, traverse speed, and groove width, while the model output was wear rate. ANN was compared with response surface methodology (RSM) to predict the wear behavior of FSPS made of aluminum reinforced by ceramic additives [54]. The inputs of the models were tool rotational speed, sliding speed, and load, while the model outputs were wear rate and coefficient of friction. The comparative study shows that the predictive accuracy of the ANN model is higher than that of RSM model.

From the abovementioned literature, it is realized that the application of artificial intelligence models in FSP is still in its cradle. Moreover, the developed models are feed-forward, optimized using conventional back-propagation techniques such as conjugate gradient and Levenberg-Marquardt. No previous studies were carried out on the applications of hybrid fine-tuned artificial intelligence models in modeling FSP in which conventional models are integrated with advanced metaheuristic optimizers. This motivated us to develop a new hybrid model to predict the mechanical properties and microstructure characteristics of FSPS. The developed model consists of a conventional artificial intelligence model called multi-layer perceptron (MLP) integrated with a metaheuristic optimizer called grey wolf optimizer (GWO). GWO was used as a subroutine to optimize MLP parameters instead of conventional back-propagation techniques. The proposed model was compared with a standalone MLP model based on different statistical measures. Both models were trained using experimental data of FSP employed on AA 2024 sheets reinforced by $\mathrm{Al}_{2} \mathrm{O}_{3}$ nanoparticles. The process control factors were rotational speed, traverse speed, and the number 
of FSP passes. The process responses were grain size, aspect ratio, microhardness, and ultimate tensile strength. The accuracy of the models, namely MLP and MLP-GWO, were evaluated using four statistical measures: determination coefficient, efficiency coefficient, root mean square error, and mean absolute error.

\section{Materials and Methods}

The base metals were $4 \mathrm{~mm}$ thick AA 2024 wrought aluminum alloy plates. Table 1 displays the plates' chemistry. Plates were produced and modified for the proper operation on surfaces with $5 \mathrm{~mm}$ wide and $2 \mathrm{~mm}$ deep rectangular grooves. The AA 2024 plates were strengthened with $30 \mathrm{~nm} \mathrm{Al} \mathrm{O}_{3}$ nanoparticles. The FSP tool used to fabricate the materials were created using the methodology explained in [55], resulting in the utilization of H13 steel. FSP was performed utilizing an automated vertical milling machine (Knuth-VFM5, Knuth, Wasbek, Germany) with three processing passes with 900, 1200, and 1500 rpm rotational speeds. During fabrication, the FSP tool's tilt angle was set at $2^{\circ}$. The experimental setup and the fabrication process of the surface composite are shown in Figure 1.

Table 1. Chemical composition of the AA 2024 base metal (\%).

\begin{tabular}{ccccccccc}
\hline $\mathbf{C u}$ & $\mathbf{M g}$ & $\mathbf{M n}$ & $\mathbf{Z n}$ & $\mathbf{F e}$ & $\mathbf{S i}$ & $\mathbf{P b}$ & Other & $\mathbf{A l}$ \\
\hline 4.81 & 1.5 & 0.62 & 0.15 & 0.2 & 0.1 & 0.02 & 0.6 & 92 \\
\hline
\end{tabular}
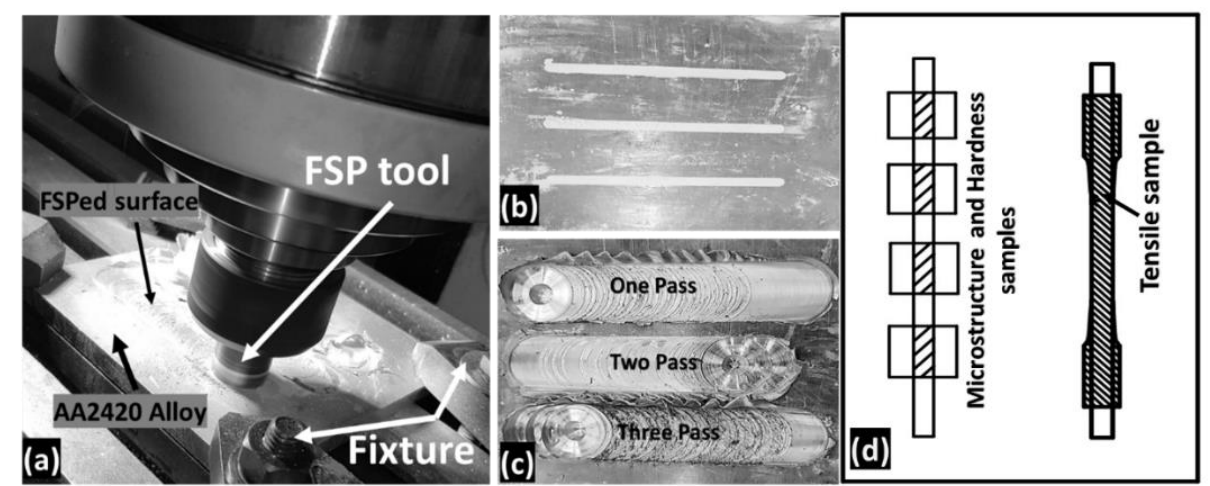

Figure 1. (a) Friction stir processing using milling machine, (b) the preparation of the AA2024 sheet filled with $\mathrm{Al}_{2} \mathrm{O}_{3}$ nanoparticles, and (c) composite surface with different FSP passes. (d) The orientation of the tensile, hardness, and microstructure samples.

All samples were sliced, sectioned, and ground prior to etching using Keller's reagent ( 2 drops $\mathrm{HF}(48 \%)+6 \mathrm{~mL} \mathrm{HNO}_{3}+90$ pure water). After a few seconds of etching at room temperature, the microstructure of FSPS was explored using an optical microscope (BX51, Olympus, Tokyo, Japan). The microstructures and hardness samples were sectioned perpendicular to the processing direction. In contrast, the tensile samples were sectioned along with the processing direction (parallel to the FSP direction), as illustrated in the schematic drawing in Figure 1d. An inverted metal microscope (Olympus GX41, Tokyo, Japan) examined the sample, while a transmission electron microscope (TEM) was used to study the $\mathrm{Al}_{2} \mathrm{O}_{3}$ nanoceramics (JEOL JSM-200F, Tokyo, Japan). We utilized a Branson CPX5800H-E ultrasonic bath (Emerson, St. Louis, MO, USA) from the United States to fully scatter the powders and then uploaded the sample onto a copper-coated 200 mesh carbon grid to determine the particle size distribution. Figure 2 shows the TEM image of the alumina nanoparticles, with an average particle size of $11.3 \pm 2 \mathrm{~nm}$. The alumina nanoparticles were found to have a crystalline polymorphic phase $\alpha-\mathrm{Al}_{2} \mathrm{O}_{3}$ and appear in white powder. 


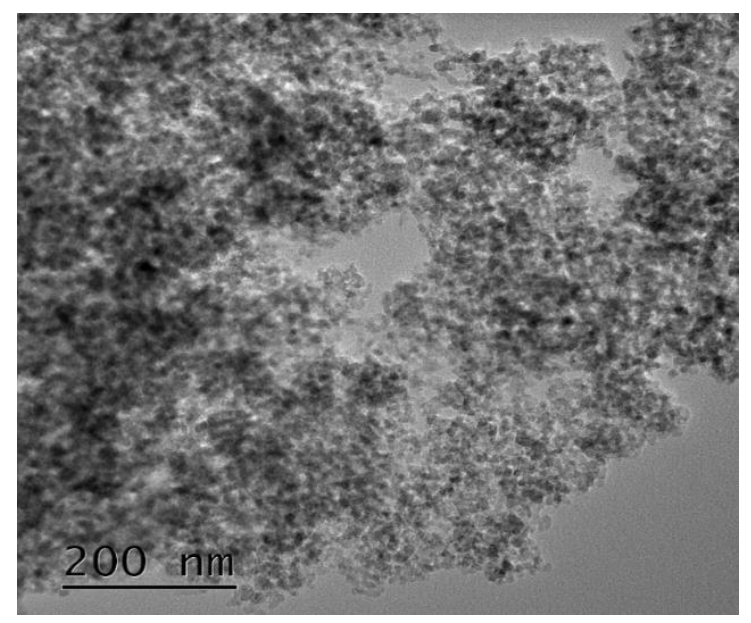

Figure 2. TEM image of $\mathrm{Al}_{2} \mathrm{O}_{3}$ nanoparticles.

The tensile tests on the specimens were carried out with the help of an MTS tension machine (MTS, Guangdong, China). The specimens were milled on a computer numerical control $(\mathrm{CNC})$ milling machine in a direction parallel to the processing direction. Each tested specimen had its applied load and extension measured and recorded.

\section{Hybrid Predictive Model}

\subsection{Multi-Layer Perceptron (MLP)}

MLP is an ANN model widely used to solve complex problems in many engineering applications such as prediction, optimization, modeling, pattern recognition, and clustering. It consists of three main layers: an input layer used to receive data, an output layer used to produce computed data, and one or more hidden layers to link the input and output layers, as shown in Figure 3. Each layer contains some perceptrons, which mimic the biological behavior of the neurons of the nervous system. Synaptic weights represent the connections between the perceptrons. These weights are adjusted during the training process of the MLP model by applying a suitable optimization process. The experimental datasets were normalized before using them in the training of the models using the following equation [56]:

$$
D_{i}=0.1+0.8\left(\frac{d_{i}-d_{\min }}{d_{\max }-d_{\min }}\right)
$$

where, $D_{i}, d_{i}, d_{\min }$ and $d_{\max }$ denote the normalized data, experimental data, minimum value of the experimental data, and maximum value of the experimental data, respectively.

The training data is fed-forward to the MLP model in which it is subjected to some mathematical operations to compute the response of the model. These mathematical operations are executed by the perceptrons in different layers and have two sequential steps. The first operation is the summation of the weight products and each perceptron input value.

$$
x_{n}=\sum_{m=1} w_{m n} y_{m}+b
$$

where $w_{m n}$ denotes the synaptic weight, $y_{m}$ denotes the input signal of the perceptron, $m$ and $n$ are the hidden and output layers, $b$ denotes the bias, and $x_{n}$ denotes the summation output, which is used as an input to the transfer function.

The computed value is introduced into a suitable transfer function to limit the output range of the perceptron. The sigmoid function is the commonly used activation function that limits the output value $\left(y_{n}\right)$ between zero and one; it is given by:

$$
y_{n}=\frac{1}{1+e^{-x_{n}}}
$$



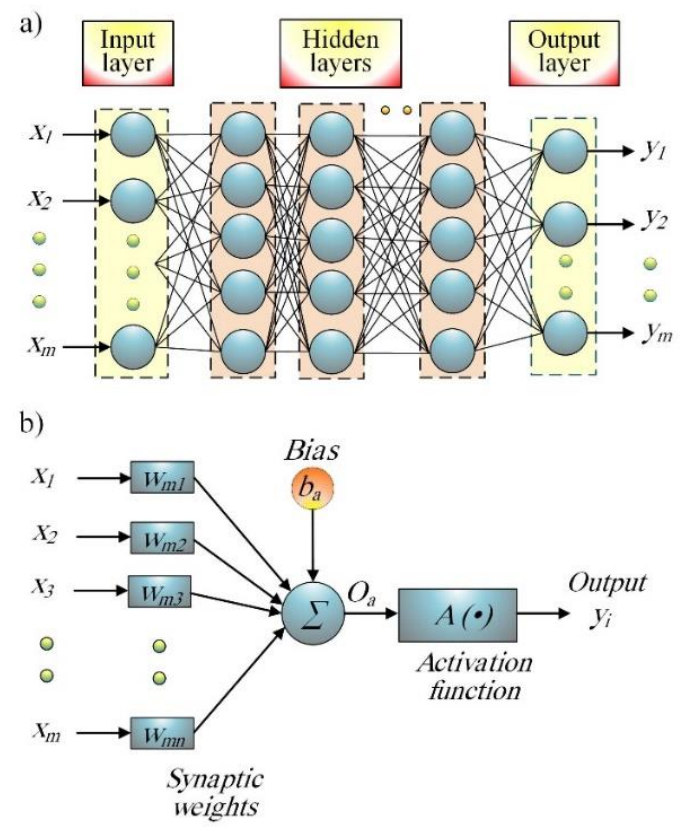

Figure 3. (a) The structure of MLP model and (b) a perceptron with a bias, summing, and activation functions.

To optimize the network, the experimental datasets should be divided into two groups, namely the learning or training group used to optimize the weights and the testing group used to check the generalization level of the model. During the training process, the data is introduced to the model, and it computes a response. The computed response is compared with the target value obtained from the experimental results to calculate the prediction error using a suitable error measure such as mean square error (MSE), which is given as:

$$
M S E=\frac{1}{N} \sum_{N}(E(x)-P(x))^{2}
$$

where $N, P(x)$, and $E(x)$ denote the number of training vectors, predicted data, and experimental data, respectively. Based on the calculated error between the responses and the target data, the weights of the network are updated using the following formula:

$$
w_{n}=w_{o}-\xi \frac{\delta e_{i}}{\delta w_{0}}
$$

where $w_{n}, w_{0}, \xi$, and $e_{i}$ denote the new weight, old weight, learning rate, and computed error, respectively. $\frac{\delta e_{i}}{\delta w_{0}}$ is the derivative of the computed error with respect to the old weight.

The aim of the weights' optimization could be achieved by decreasing the mean squared error (MSE) value to obtain more accurate responses. MSE is used as a cost function during the optimization process. Once the weights' optimization is accomplished, the testing data is presented to the model. The predicted results are compared with the experimental ones to evaluate the model accuracy using different statistical measures presented in Table 2.

To obtain an accurate MLP model, the network was trained using $85 \%$ of the experimental data and tested using the remaining data. Besides the weights' optimization, there are several parameters, which should be optimized to obtain an accurate model, such as the number of hidden layers and perceptrons, learning rate, and learning coefficients. 
Table 2. Statistical measures used for model evaluation [57].

\begin{tabular}{cccc}
\hline Statistical Measure & Abbreviation & Formula & Optimal Value \\
\hline $\begin{array}{c}\text { Determination } \\
\text { coefficient }\end{array}$ & $R^{2}$ & $\frac{\left(\sum_{i=1}^{N}(E(x)-\overline{E(x)})(P(x)-\overline{P(x)})\right)^{2}}{\sum_{i=1}^{N}(E(x)-\overline{E(x)})^{2} \times \sum_{i=1}^{N}(P(x)-\overline{P(x)})^{2}}$ & Approach unity \\
$\begin{array}{c}\text { Efficiency coefficient } \\
\text { Root mean square } \\
\text { error }\end{array}$ & $E C$ & $1-\frac{\sum_{i=1}^{N}(E(x)-P(x))^{2}}{\sum_{i=1}^{N}(E(x)-\overline{E(x)})^{2}}$ & Approach unity \\
Mean absolute error & RMSE & $\sqrt{\frac{1}{N} \sum_{i=1}^{N}(E(x)-P(x))^{2}}$ & Approach zero \\
& $M A E$ & $\frac{1}{N} \sum_{i=1}^{N}|E(x)-P(x)|$ & Approach zero \\
\hline
\end{tabular}

\subsection{Grey Wolf Optimizer (GWO)}

GWO is a swarm-based metaheuristic optimizer that mimics the social behavior of wolves during the hunting of prey [58]. Wolves are arranged into three main groups; namely, the first one is the fittest group represented by $\alpha$, the other two normal groups are represented by $\beta$ and $\delta$. The fittest wolves mange the search process for the prey. The other two normal groups follow the fittest one during the search process within the search space. The hunting behavior of the wolves could be represented by three stages, namely encircling, tracking, and attacking the prey. The encircling stage is mathematically formulated as follows:

$$
\begin{aligned}
& \Delta(s+1)=\left|C \cdot X_{p}(s+1)-X(s+1)\right| \\
& X(s+1)=\left|X_{p}(s+1)-D \cdot \Delta(s+1)\right|
\end{aligned}
$$

where $\Delta$ denotes the distance between prey $X_{p}$ and wolf $X$, and $C$ and $D$ are coefficient vectors given by:

$$
\begin{gathered}
C=2 v_{1} \\
D=2 a v_{2}-a
\end{gathered}
$$

where $v_{1}$ and $v_{2}$ denote random vectors ranges between 0 and 1 , and $a$ is a linearly decreased vector.

The position of any wolf $X$ is updated based on the position of the three main groups $(\alpha, \beta$, and $\delta)$ of the wolves as follows:

$$
X(s+1)=\frac{X_{e}+x_{t}+X_{a}}{3}
$$

where

$$
\begin{aligned}
& X_{e}=\left|X_{\alpha-} U_{\alpha} V_{\alpha}\right|, X_{t}=\left|X_{\beta-} U_{\beta} V_{\beta}\right|, X_{a}=\left|X_{\delta-} U_{\delta} V_{\delta}\right| \\
& V_{\alpha}=\left|C_{1} X_{\alpha}-X\right|, V_{\beta}=\left|C_{2} X_{\beta}-X\right|, V_{\delta}=\left|C_{3} X_{\delta}-X\right|
\end{aligned}
$$

Figure 4 shows the behavior of wolves during the search process to update their position based on encircling, tracking, and attacking groups in a two-dimensional search space. Once the position of the prey is estimated, and the positions of wolves are updated randomly around the prey based on the aforementioned formulas.

\subsection{Fine-Tuned Model}

The MLP model is optimized using GWO, which acts as a subroutine embedded into the model. GWO is used as an internal optimizer instead of conventional back-propagation algorithms such as conjugate gradient and Levenberg-Marquardt, to optimize the weights and biases of the network that maximize the prediction accuracy. The use of GWO may help in overcoming the problems of these conventional algorithms, such as trapping into local minima and slow convergence speeds. The training process of the MLP with GWO starts with initializing the weights and biases of MLP model randomly. The training samples from the training dataset are fed into the network. The MLP model computes the output and 
compares it with the target based on an error criterion such as MSE given in Equation (4). This computed error is used as an objective function that should be minimized to maximize the model accuracy. The GWO is implemented using these random values to compute the next set of biases and weights for the next iteration. The implementation of GWO is repeated until the stopping criterion is fulfilled. Finally, the network parameters with the minimum error from all executed iterations are considered as the optimal solution. The flow chart of the implemented MLP-GWO model is given in Figure 5.

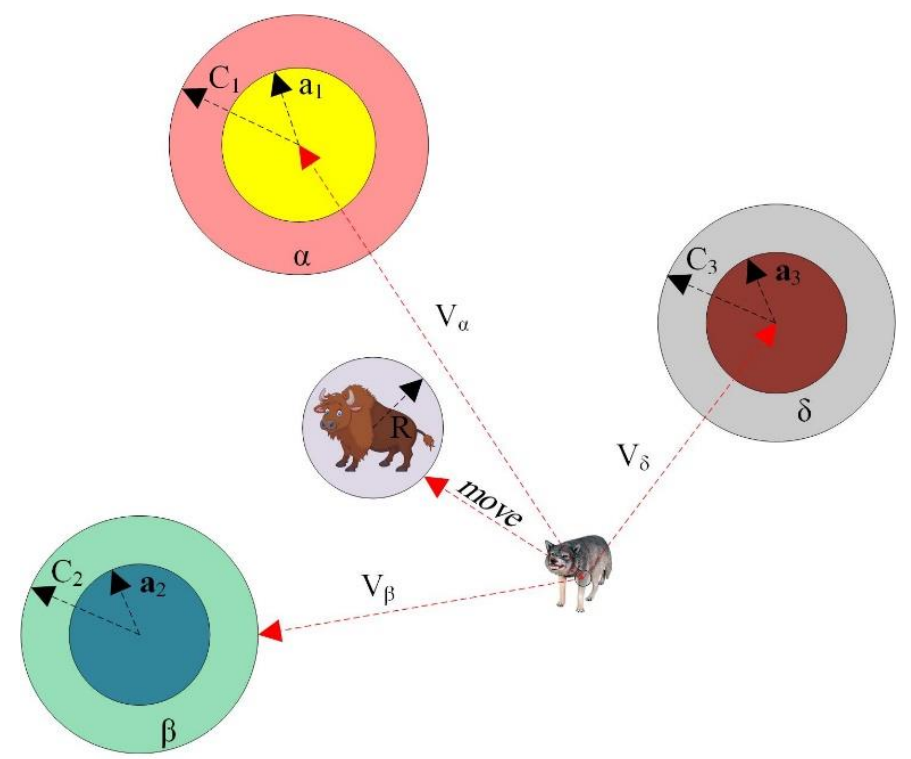

Figure 4. Grey Wolf Optimizer.

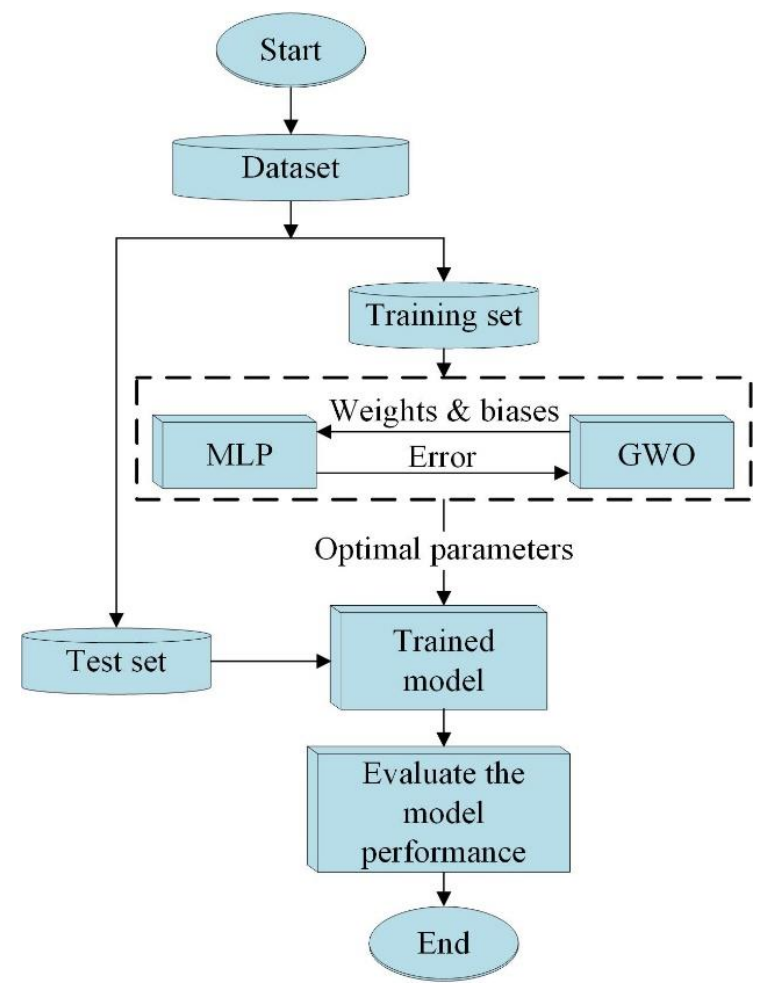

Figure 5. Flow chart of the hybrid MLP-GWO model. 


\section{Results and Discussions}

This section will discuss three topics: microstructural observation, mechanical properties evaluation, and validation of the predictive models. The experiments are conducted using various combinations of process control factors, namely rotational, traverse speed, and number of FSP passes. Four process responses are measured: the grain size, aspect ratio, microhardness, and ultimate tensile strength. The effects of the process factors on the responses will be demonstrated to figure out the relationship between them. Then, the experimental data presented in Table 3 are used to train and test the developed MLP and MLP-GWO models. The accuracy of the models is evaluated using statistical measures.

Table 3. Experimental data.

\begin{tabular}{|c|c|c|c|c|c|c|c|}
\hline $\begin{array}{l}\text { Specimen } \\
\text { Code }\end{array}$ & $\begin{array}{c}\text { Rotational } \\
\text { Speed (rpm) }\end{array}$ & $\begin{array}{c}\text { Traverse } \\
\text { Speed } \\
\text { (mm/min) }\end{array}$ & $\begin{array}{c}\text { Number of } \\
\text { Passes }\end{array}$ & $\begin{array}{c}\text { Grain Size } \\
(\mu \mathrm{m})\end{array}$ & Aspect Ratio & $\begin{array}{c}\text { Micro-Hardness } \\
\text { (HV) }\end{array}$ & $\begin{array}{l}\text { Ultimate Tensile } \\
\text { Strength (MPa) }\end{array}$ \\
\hline 1 & 1120 & 10 & 1 & 25.4275 & 0.486825 & 68.2 & 258.993 \\
\hline 2 & 1120 & 15 & 1 & 30.2 & 0.481 & 98.4 & 239.1106 \\
\hline 3 & 1120 & 20 & 1 & 24.8175 & 0.48175 & 88.8 & 209.9856 \\
\hline 4 & 1500 & 10 & 1 & 42.825 & 0.281 & 68.8 & 195.0305 \\
\hline 5 & 1500 & 15 & 1 & 44.8375 & 0.418 & 78.8 & 188.1139 \\
\hline 6 & 1500 & 20 & 1 & 26.075 & 0.259 & 96.4 & 176.9834 \\
\hline 7 & 900 & 10 & 1 & 32.75875 & 0.4215 & 68 & 190.1551 \\
\hline 8 & 900 & 15 & 1 & 22.2825 & 0.4425 & 84.4 & 230.3401 \\
\hline 9 & 900 & 20 & 1 & 26.595 & 0.335975 & 83.2 & 195.6401 \\
\hline 10 & 1800 & 10 & 1 & 35.165 & 0.45825 & 91.6 & 239.675 \\
\hline 11 & 1800 & 15 & 1 & 26.91875 & 0.4045 & 100.8 & 120.7028 \\
\hline 12 & 1800 & 20 & 1 & 22.1475 & 0.34325 & 93.4 & 94.10151 \\
\hline 13 & 1120 & 10 & 2 & 26.075 & 0.40025 & 64.4 & 301.2278 \\
\hline 14 & 1120 & 15 & 2 & 31.91 & 0.34825 & 83.4 & 260.5566 \\
\hline 15 & 1120 & 20 & 2 & 33.125 & 0.37425 & 96.8 & 246.3574 \\
\hline 16 & 1500 & 10 & 2 & 26.6125 & 0.4375 & 75.4 & 217.8233 \\
\hline 17 & 1500 & 15 & 2 & 24.475 & 0.3275 & 105.4 & 165.6143 \\
\hline 18 & 1500 & 20 & 2 & 20.6675 & 0.4125 & 96.2 & 133.4589 \\
\hline 19 & 900 & 10 & 2 & 36.26975 & 0.3765 & 91.2 & 293.0167 \\
\hline 20 & 900 & 15 & 2 & 5.399 & 0.7575 & 69.6 & 234.7553 \\
\hline 21 & 900 & 20 & 2 & 59.565 & 0.49175 & 72.2 & 224.2906 \\
\hline 22 & 1800 & 10 & 2 & 31.83 & 0.3765 & 102.8 & 273.9346 \\
\hline 23 & 1800 & 15 & 2 & 21.725 & 0.478 & 77.6 & 236.1191 \\
\hline 24 & 1800 & 20 & 2 & 29.6175 & 0.2375 & 88.2 & 313.7088 \\
\hline 25 & 900 & 10 & 3 & 7.475 & 0.77425 & 66.4 & 305.9897 \\
\hline 26 & 900 & 15 & 3 & 3.425 & 0.76125 & 109.6 & 273.9346 \\
\hline 27 & 900 & 20 & 3 & 28.9925 & 0.24975 & 71.4 & 236.1191 \\
\hline 28 & 1120 & 10 & 3 & 11.81 & 0.73075 & 84.4 & 313.7088 \\
\hline 29 & 1120 & 15 & 3 & 7.9675 & 0.78325 & 103 & 276.0911 \\
\hline 30 & 1120 & 20 & 3 & 9.06375 & 0.72975 & 101.4 & 271.6196 \\
\hline 31 & 1500 & 10 & 3 & 23.7 & 0.41375 & 62.4 & 287.8736 \\
\hline 32 & 1500 & 15 & 3 & 24.7825 & 0.27875 & 79.8 & 211.0938 \\
\hline 33 & 1500 & 20 & 3 & 25.2375 & 0.45125 & 100.2 & 168.7652 \\
\hline 34 & 1800 & 10 & 3 & 28.925 & 0.44275 & 103.8 & 209.1876 \\
\hline 35 & 1800 & 15 & 3 & 5.905 & 0.72025 & 106.2 & 162.8843 \\
\hline 36 & 1800 & 20 & 3 & 5.3915 & 0.41725 & 94.2 & 89.71616 \\
\hline
\end{tabular}

\subsection{Microstructural Observation}

The FSP processing parameters have a significant impact on microstructural behavior. Using the JMicroVision software, the average grain intercept approach was used to compute microstructural grain sizes (Roduit, N. JMicroVision, version 1.3.1, Switzerland). The AA 2024 base metal was observed to have a grain size of $130 \mu \mathrm{m}$. Refinement of grain is seen in Figure 6. After the first pass, the grains size was reduced to $35 \mu \mathrm{m}$ under ideal FSP processing conditions. Increasing the FSP passes enhances the third pass's microstructural grain refining process by less than $7 \mu \mathrm{m}$. Multiple FSP passes improved $\mathrm{Al}_{2} \mathrm{O}_{3}$ nanoparticle dispersion and surface homogeneity in MMNCs (Figure 7). Rotational speed influenced microstructural grain refinement during FSP, increasing the average grain size. This is owing to the relationship between rotational speed and the heat generated during the FSP 
process. There is a significant effect of the multiple processing passes on the mechanical and the microstructure grain refinement. This grain refinement occurred during the dynamic recrystallization process of the friction stir action. The grain refinement enhances the mechanical properties by increasing the processed alloy's ductility and plastic deformation behavior.
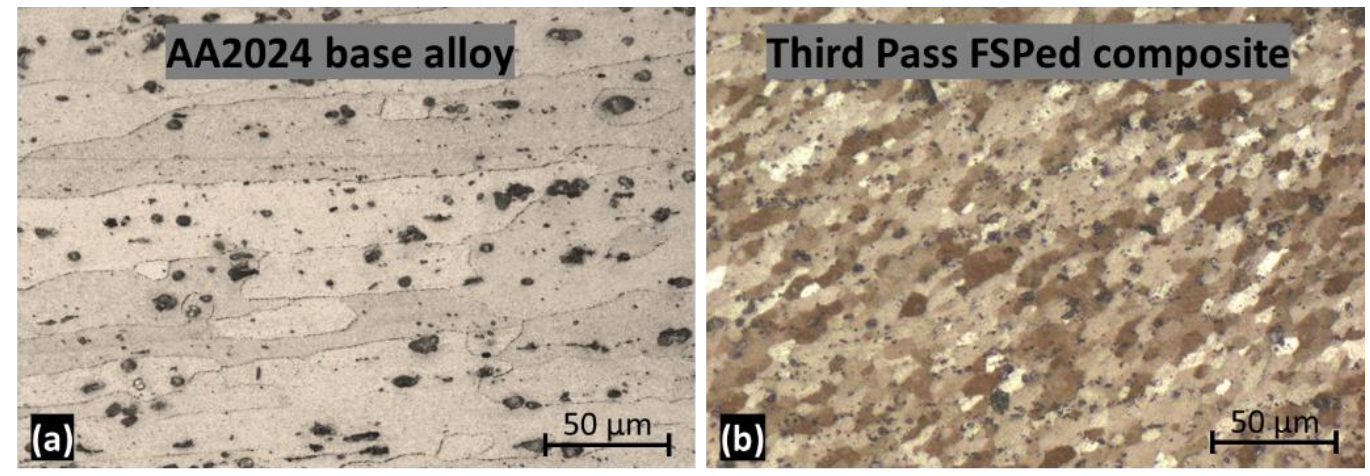

Figure 6. Optical microstructure image of the as-received AA2024 alloy (a), and (b) the FSPed at the third pass.

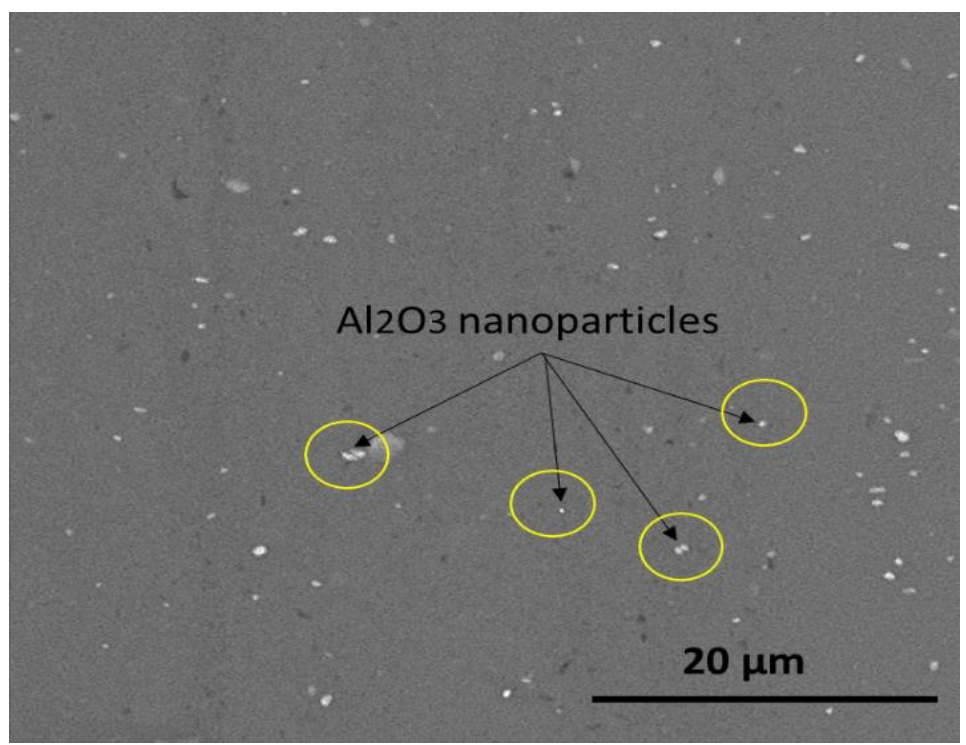

Figure 7. SEM image of the fabricated composite.

By increasing FSP passes, a low rotating speed helps to improve the microstructural refinement process. Furthermore, a single pass is unreliable for ceramic or hardened particle surfaces due to the accumulation of the reinforcement particles in the first pass. In contrast, more FSP passes to increase the dispersion and distribution of such particles in the metal matrix. Thus, the type and number of reinforced particles used in the fabrication process affect FSP heat generation.

\subsection{Effect of Tool Rotational and Traverse Speed on Ultimate Tensile Strength}

Ultimate tensile strength curves are represented in the comparison form. The effect of rotation speed on the ultimate tensile strength throughout different passes number has been investigated. Tool rotations speed performed at 900 and $1120 \mathrm{rpm}$ has a higher ultimate tensile strength than other speeds, especially when processed at 10 and $15 \mathrm{~mm} / \mathrm{min}$ traverse speeds. The third pass causes an improvement in the tensile strength. The maximum value for UTS is improved by $27 \%$ rather than the base metal. The tool rotation speed at $1800 \mathrm{rpm}$ remarked that having a lower UTS over the three passes performed. 
Figure 8 shows the ultimate tensile strength UTS curves in the comparison form through different processing parameters of traverse speed and number of FSP passes. The effect of rotation speed on the ultimate tensile strength throughout different passes number has been investigated. Tool rotations speed performed at 900 and $1120 \mathrm{rpm}$ has a higher ultimate tensile strength than other speeds, especially when processed at 10 and $15 \mathrm{~mm} / \mathrm{min}$ traverse speeds. The third pass causes an improvement in the tensile strength. The maximum value for UTS is improved by $27 \%$ rather than the base metal. The tool rotation speed at $1800 \mathrm{rpm}$ remarked that having a lower UTS over the three passes performed. Additionally, the feed rate influences the mechanical characteristics of Al-alloys. The tool rotation speed in conjunction with an appropriate traverse speed is a critical parameter in the FSP. With a relatively modest traverse rate of 10 and $15 \mathrm{~mm} / \mathrm{min}$, enhanced results for these metal matrix composites are obtained. The increased traversal speed utilized in friction stir processed FSPed for the nanocomposite matrix did not result in an adequate amount of heat being produced during processing. The observed data indicated that increasing the traverse speed resulted in a drop in the UTS values.
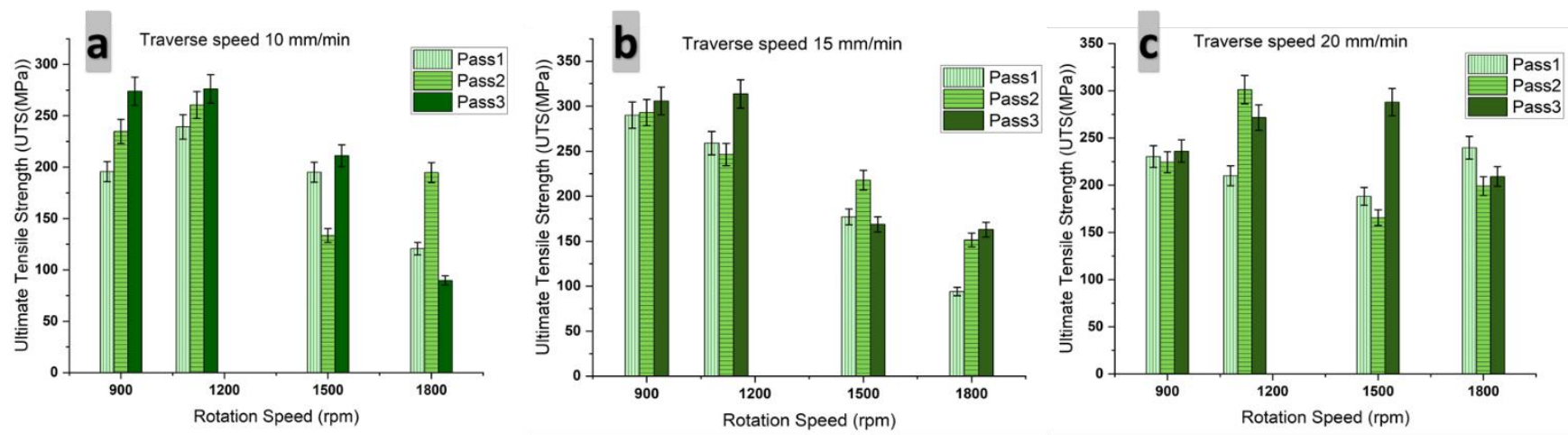

Figure 8. Effect of processing parameters on the ultimate tensile strength. (a) processing speed $10 \mathrm{~mm} / \mathrm{min}$; (b) $15 \mathrm{~mm} / \mathrm{min}$; (c) $20 \mathrm{~mm} / \mathrm{min}$.

Additionally, the feed rate influences the mechanical characteristics of Al-alloys. The tool rotation speed in conjunction with an appropriate traverse speed is a critical parameter in the FSP. With a relatively modest traverse rate of 10 and $15 \mathrm{~mm} / \mathrm{min}$, enhanced results for these metal matrix composites are obtained. The increased traversal speed utilized in FSPed for the nanocomposite matrix did not result in an adequate amount of heat being produced during processing. The observed data indicated that increasing the traverse speed resulted in a drop in the UTS values.

\subsection{Influence of Tool Speed on the Grain Size}

The number of FSP passes significantly impacts the grain structure and precipitate dispersion in FSPed samples as shown in Figure 9. The average grain size in specimen samples collected from the agitated zone. The third pass improves the average grain size with four distinct rotation rates of 900,1120,1500, and $1800 \mathrm{rpm}$, respectively, processed at $10 \mathrm{~mm} / \mathrm{min}$ travel speed. Finer grain is produced when the tool rotation speed is set at 900 RPM. Throughout all passes, the difference in average grain size is obtained at low rotation speed $(900 \mathrm{rpm})$ and high rotation speed $(1800 \mathrm{rpm})$. The multi-pass processing affects the samples processed at $900 \mathrm{rpm}$ and $10 \mathrm{~mm} / \mathrm{min}$ travel speed. The average grain size decreases as the number of passes increases. The average grain size was reduced by $75 \%$ in the third pass compared to the first. Furthermore, the aspect ratio has been increased by $50 \%$. The multi-pass FSP has no noticeable impact on grain size at 1500 rotation speed and $10 \mathrm{~mm} / \mathrm{min}$ traverse speed. The aspect ratio varies noticeably between the second and third passes. When the tool travel speed is increased to $20 \mathrm{~mm} / \mathrm{min}$ with a higher rotation speed $(1800 \mathrm{rpm})$, the development of finer grain is observed owing to a greater rotation 
to travel speed ratio. Larger grains develop when the ratio falls with increasing rotation speed. Coarse grain was discovered at lower rotating tool speeds.

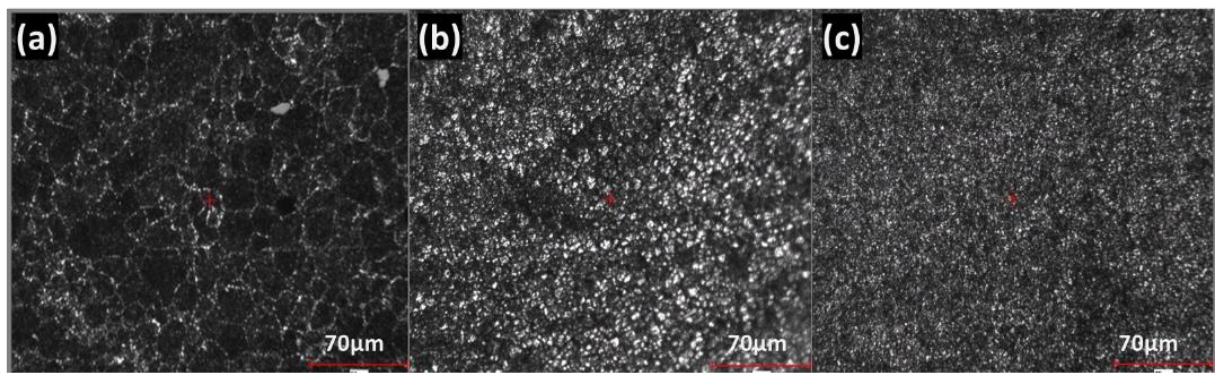

Figure 9. The effect of passes number on the microstructure refinement at rotation speed $900 \mathrm{rpm}$ and $10 \mathrm{~mm} / \mathrm{min}$ traverse speed; (a) first pass, (b) second pass, and (c) third pass.

\subsection{Validation of the Predictive Model}

To evaluate the capability of the developed MLP-GWO model to predict the mechanical properties and microstructure characteristics of the prepared FSPS, it is compared with standalone MLP. The inputs of MLP and MLP-GWO models are rotational speed, traverse speed, and number of FSP passes, while the outputs are grain size, the aspect ratio of grains, microhardness, and tensile strength. The total number of the measured datasets used to train and test the models was 36 datasets, $85 \%$ were used to train the models, and the remaining $15 \%$ were used to test the models. The testing sets were selected randomly from the experimental sets. Each response has its own testing set. For grain size the indices of the testing sets are 4,5,12,23, and 26. For aspect ratio the indices of the testing sets are $3,6,14,25$, and 34 . For microhardness the indices of the testing sets are 9, 20, 21, 29, and 34. For ultimate tensile strength the indices of the testing sets are 9, 12, 22, 25, and 35 . These data are normalized using before using it in the training process using Equation (1). The convergence plots of MLP and MLP-GWO models during the training processes of all predicted responses are shown in Figure 10. The MLP-GWO model convergences faster than MLP model for all predicted responses. Moreover, the computed MSE in the case of MLP-GWO is lower than that of standalone MLP. Less than $0.02 \mathrm{~s}$ is elapsed for execution a single iteration of the model on a desktop computer (Intel(R) Core(TM) i5-3470 CPU @ 3.20GHz) using MATLAB R2020a.

Figure 11 shows the predicted grain size, aspect ratio of grains, microhardness, and tensile strength versus the measured ones. All predicted responses using MLP-GWO (in blue) are in a better agreement with the predicted ones (in black) compared with that of standalone MLP (in red). This agreement between the results of MLP-GWO and experimental data indicates the important role of GWO in enhancing the performance of the MLP model compared with the classical optimization techniques.

Figure 12 presents the normalized error plots and the error histograms for all investigated responses. The normalized error for the results obtained by MLP-GWO is much lower than that of standalone MLP, which indicates the importance of GWO to boost the performance of the MLP model. In the case of grain size, the normalized error ranges between $-1-0.5$ and $-0.2-0.2$ for MLP and MLP-GWO, respectively; while it ranges between $-0.5-0.5$ and $-0.2-0.2$ in the case of aspect ratio, it ranges between $-0.2-0.2$ and $-0.1-0.1$ in the case of microhardness, and it ranges between $-0.2-0.2$ and $-0.07-0.07$ in the case of tensile strength. The error histograms show that the error distribution of MLP-GWO results is much lower than that of MLP results for all predicted responses. The low normalized error and the tight distribution of the error of the results obtained by MLP-GWO indicate its enhanced accuracy compared with standalone MLP. 


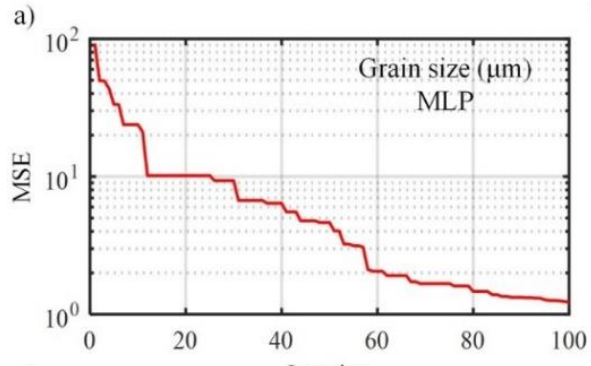

c)
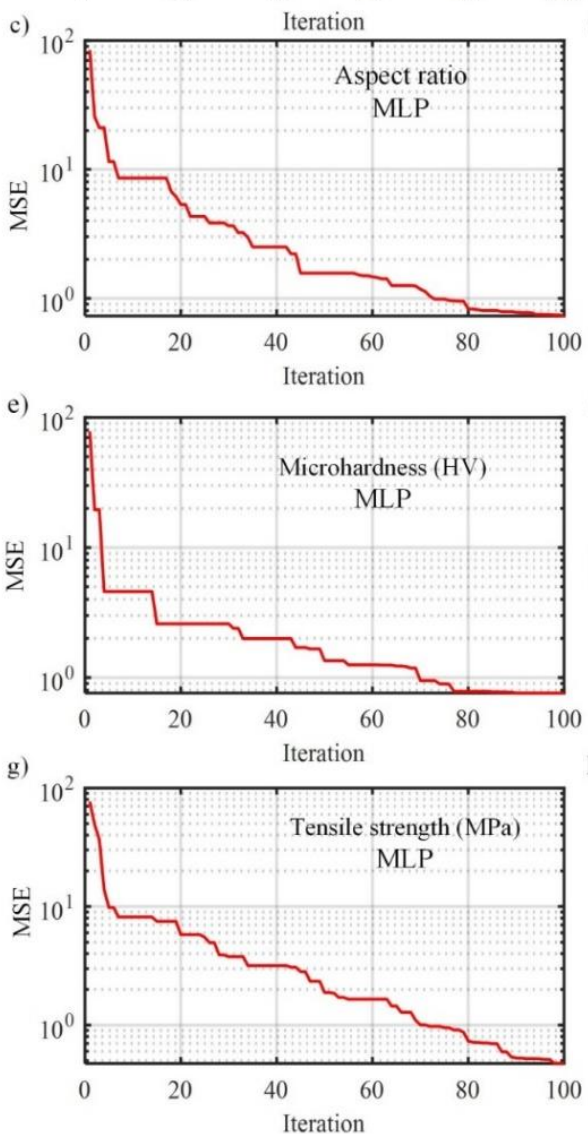

b)
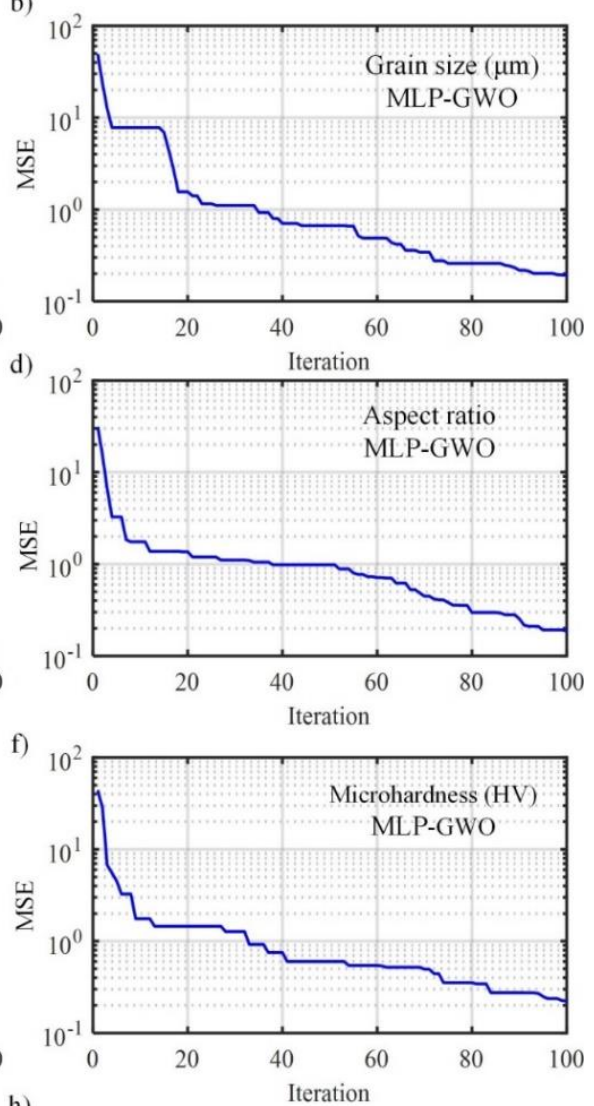

h)

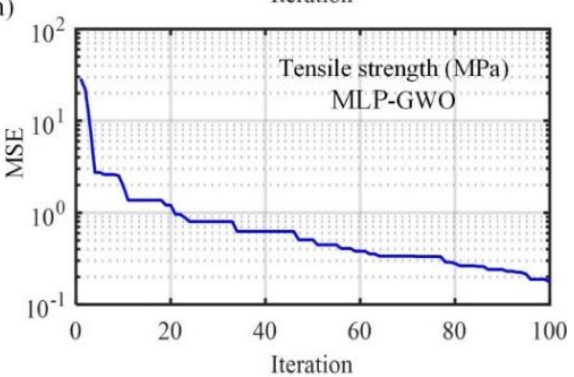

Figure 10. Convergence plots of MLP and MLP-GWO models. (a) grain size (MLP); (b) grain size (MLP-GWO); (c) aspect ratio (MLP); (d) aspect ratio (MLP-GWO); (e) micro-hardness (MLP); (f) micro-hardness (MLP-GWO); (g) tensile strength (MLP); (h) tensile strength (MLP-GWO).

Figure 13 shows QQ plots for all predicted responses, particularly grain size, aspect ratio, microhardness, and tensile strength using MLP and MLP-GWO. In these plots, the spread of plotted points away from the straight line reveals the deficiency of the predictive model. The predicted responses of MLP have a poor fitting with the experimental ones for all predicted responses (red color plots), while the predicted responses of MLP-GWO have a good fitting with the experimental ones for all investigated cases (blue color plots). QQ plots are another indicator of the outperformance of MLP-GWO over standalone MLP. 

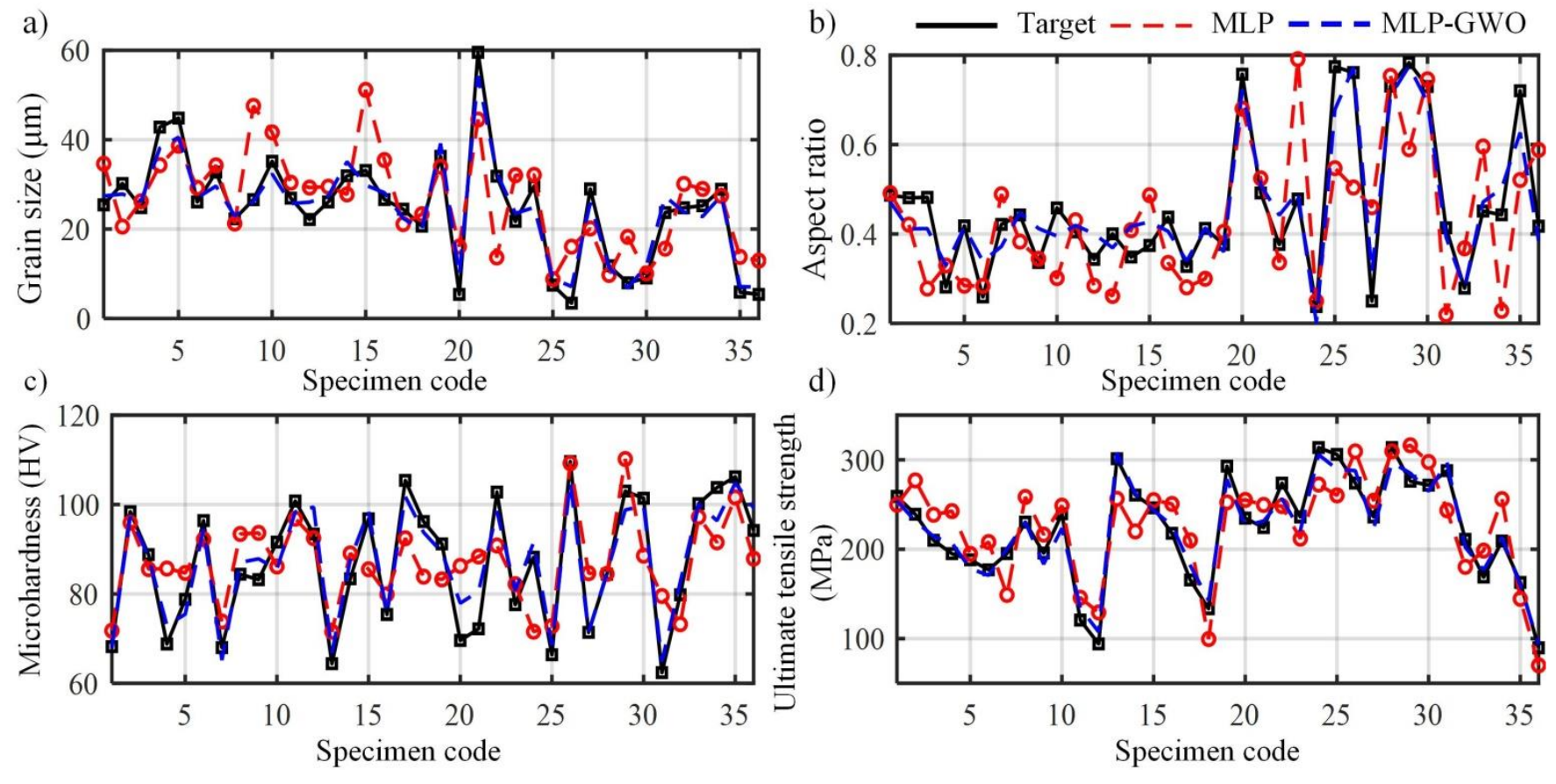

Figure 11. The measured and predicted data using MLP and MLP-GWO for: (a) grain size, (b) aspects ratio, (c) microhardness, and (d) ultimate tensile strength.
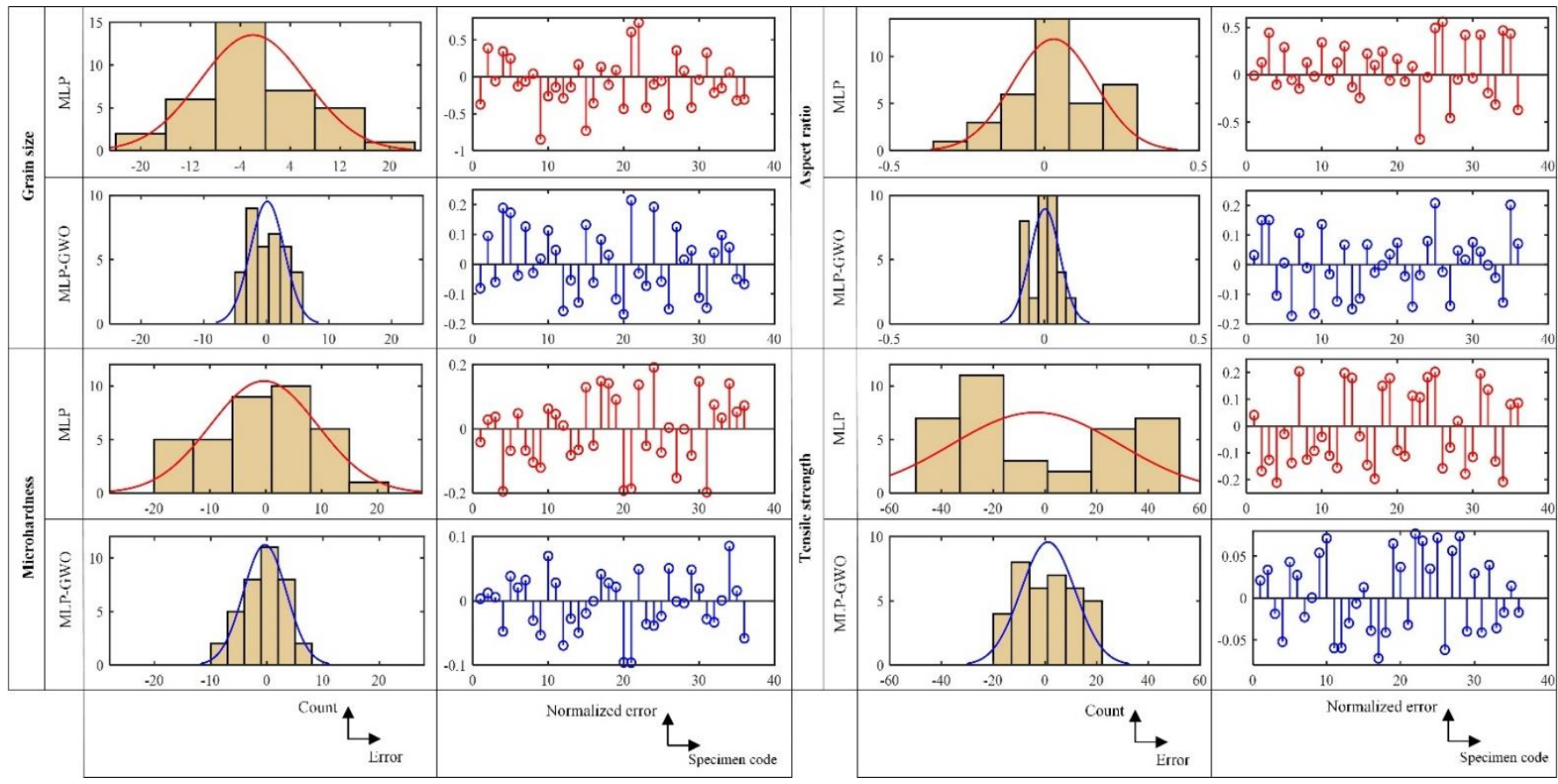

Figure 12. The normalized error plots and error histograms for all predicted responses using MLP and MLP-GWO.

The accuracy of MLP and MLP-GWO models is evaluated using four statistical measures, namely $\mathrm{R}^{2}$, EC, RMSE, and MAE as tabulated in Table 4 . MLP-GWO has the highest $R^{2}$ ranges between $0.915-0.971$, and MLP has the lowest $R^{2}$ ranges between $0.416-0.715$. $\mathrm{R}^{2}$ of MLP-GWO is higher than that of standalone MLP by about 79.924, 119.952, 75.329, and 35.804 for grain size, the aspect ratio of grains, microhardness, and tensile strength, respectively. MLP-GWO also has the highest EC ranges between 0.909-0.968 and MLP has the lowest EC ranges between 0.271-0.705. EC of MLP-GWO is higher than that of standalone MLP by about $98.535,235.424,74.669$, and 37.695 for grain size, the aspect ratio 
of grains, microhardness, and tensile strength, respectively. The high $\mathrm{R}^{2}$ and EC values of MLP-GWO results compared with standalone MLP reveal the high correlation between the predicted results of MLP-GWO and the experimental ones, and consequently, the high accuracy of the MLP-GWO model to predict the mechanical properties and microstructure characteristics of the prepared FSPS. On the other hand, MLP-GWO has the lowest RMSE and MAE range between 0.047-10.411 and 0.038-9.291, respectively, while MLP has the highest RMSE and MAE range between $0.134-32.160$ and $0.107-29.662$, respectively.

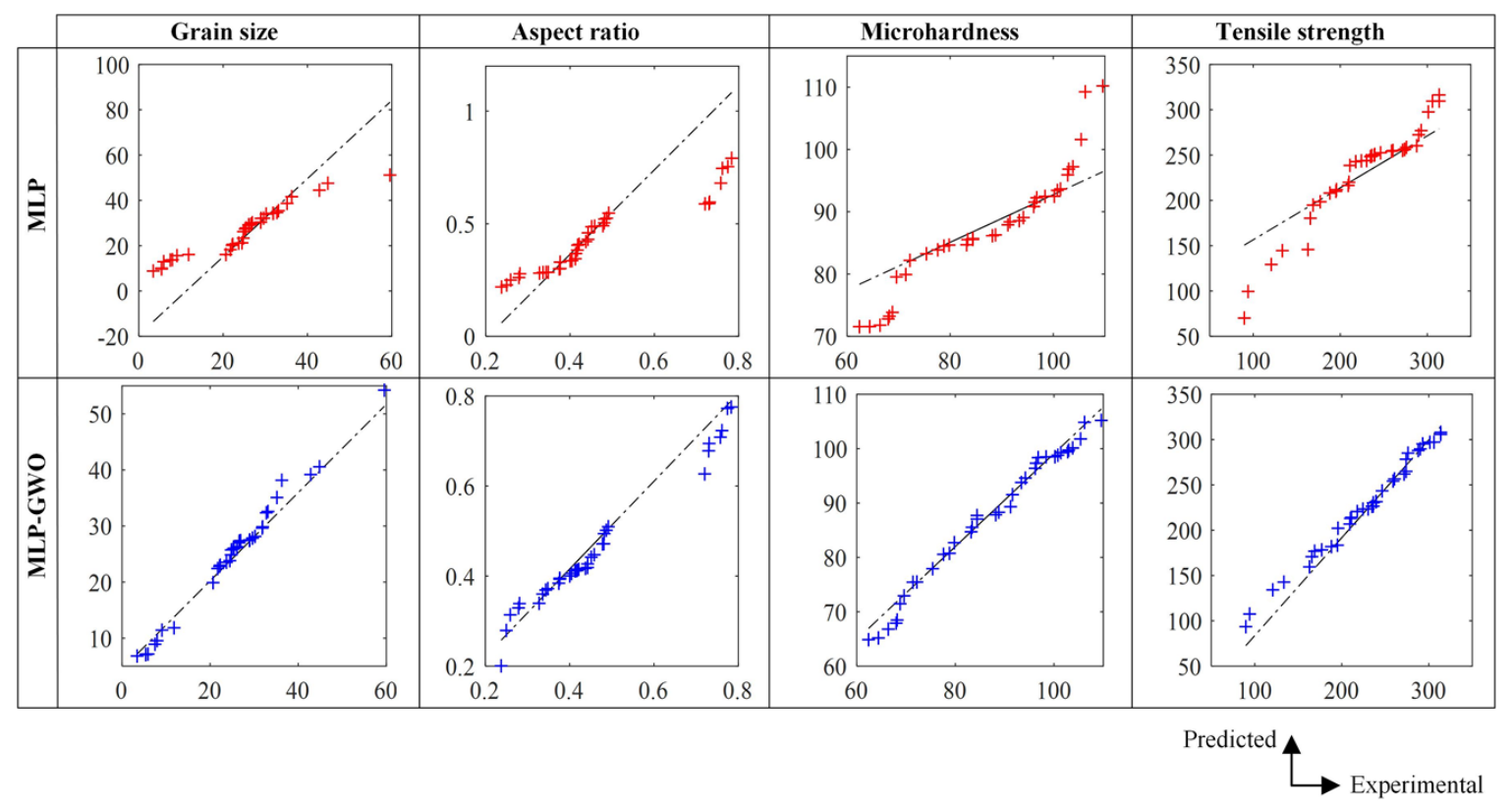

Figure 13. QQ plots for all predicted responses using MLP and MLP-GWO.

Table 4. Evaluation of MLP and MLP-GWO results using statistical measures.

\begin{tabular}{cccccc}
\hline \multicolumn{2}{c}{ Algorithm } & $\mathbf{R}^{\mathbf{2}}$ & EC & RMSE & MAE \\
\hline \multirow{2}{*}{ Grain size } & MLP & 0.533 & 0.478 & 8.611 & 6.904 \\
& MLP-GWO & 0.959 & 0.949 & 2.68 & 2.321 \\
\hline \multirow{2}{*}{ Aspect ratio } & MLP & 0.416 & 0.271 & 0.134 & 0.107 \\
& MLP-GWO & 0.915 & 0.909 & 0.047 & 0.038 \\
\hline \multirow{2}{*}{ Grain size } & MLP & 0.531 & 0.529 & 9.461 & 8.049 \\
& MLP-GWO & 0.931 & 0.924 & 3.7942 & 3.101 \\
\hline \multirow{2}{*}{ Aspect ratio } & MLP & 0.715 & 0.703 & 32.160 & 29.662 \\
& MLP-GWO & 0.971 & 0.968 & 10.411 & 9.291 \\
\hline
\end{tabular}

RMSE of MLP-GWO is lower than that of standalone MLP by about $68.877,64.925$, 59.896, and 67.627; while MAE for MLP-GWO is lower than that of MLP by about 66.381, $64.485,61.473$, and 68.677 for grain size, an aspect ratio of grains, microhardness, and tensile strength, respectively. The low values of RMSE and MAE of MLP-GWO predicted results compared with standalone MLP reveal the high accuracy of the MLP-GWO model to predict the prepared mechanical properties and microstructure characteristics FSP.

From the aforementioned analysis, it could be realized that the use of GWO as subroutines in the conventional MLP model improves the model accuracy via optimizing the internal parameters of the network. Generally, the incorporation between MLP and advanced metaheuristic optimizers such as GWO is recommended as an alternative to conventional MLP models to predict the mechanical properties and microstructure characteristics of the prepared FSPS. 


\section{Conclusions}

In this study, an optimized multilayer perceptrons model using grey wolf optimizer is developed to predict mechanical and microstructural properties of friction stir processed aluminum alloy reinforced by alumina nanoparticles. The inputs of the model were rotational speed, linear processing speed, and number of passes; while the outputs were grain size, aspect ratio, microhardness, and ultimate tensile strength. The prediction accuracy of the developed hybrid model was compared with that of standalone multilayer perceptrons model using different error measures. The main finding of the investigation could be summarized as follows:

- Superior tensile strength is obtained at low rotating speeds of 900 and $1120 \mathrm{rpm}$, with a $15 \mathrm{~mm} / \mathrm{min}$ medium travel speed.

- Increasing the FSP passes results in grain refinement and excellent dispersion of alumina nanoparticles in the composite matrix.

- Average microhardness is enhanced by $40 \%$ in the stirring zone higher than the base metal. Regarding the grain refinement and reinforcing nanoparticles.

- The results demonstrate that there is an excellent homogeneous and dispersion of $\mathrm{Al}_{2} \mathrm{O}_{3}$ nanoparticles inside the stirring zone.

- GWO could be used as a powerful alternative to conventional back-propagation techniques to optimize MLP model.

- The hybrid MLP-GWO outperformed the standalone MLP model.

- MLP-GWO has the highest $R^{2}$ ranges between 0.915-0.971, and MLP has the lowest $R^{2}$ ranges between 0.416-0.715. $R^{2}$ of MLP-GWO is higher than that of standalone MLP by about 79.924, 119.952, 75.329, and 35.804 for grain size, the aspect ratio of grains, microhardness, and tensile strength, respectively.

Author Contributions: Data curation, A.B.K. and E.B.M.; formal analysis, O.T.B.; funding acquisition, E.B.M.; investigation, O.T.B. and A.H.E.; methodology, A.B.K.; resources, A.B.K.; software, A.H.E.; writing-original draft, E.B.M. and A.H.E.; writing-review and editing, A.H.E. All authors have read and agreed to the published version of the manuscript.

Funding: This project was funded by the Deanship of Scientific Research (DSR) at King Abdulaziz University, Jeddah (Grant No. G: 49-135-1442).

Institutional Review Board Statement: Not applicable.

Informed Consent Statement: Not applicable.

Data Availability Statement: Data sharing is not applicable to this article.

Conflicts of Interest: The authors declared that there is no conflict of interest.

\section{References}

1. Moustafa, E.B. Dynamic characteristics study for surface composite of AMMNCs matrix fabricated by friction stir process. Materials 2018, 11, 1240. [CrossRef] [PubMed]

2. AbuShanab, W.S.; Moustafa, E.B. Effects of friction stir processing parameters on the wear resistance and mechanical properties of fabricated metal matrix nanocomposites (MMNCs) surface. J. Mater. Res. Technol. 2020, 9, 7460-7471. [CrossRef]

3. Moustafa, E.B.; Mosleh, A.O. Effect of (Ti-B) modifier elements and FSP on 5052 aluminum alloy. J. Alloys Compd. 2020, 823, 153745. [CrossRef]

4. Baradeswaran, A.; Elaya Perumal, A. Study on mechanical and wear properties of $\mathrm{Al} 7075 / \mathrm{Al}_{2} \mathrm{O}_{3} /$ graphite hybrid composites. Compos. Part B Eng. 2014, 56, 464-471. [CrossRef]

5. Eskandari, H.; Taheri, R. A Novel technique for development of aluminum alloy matrix $/ \mathrm{TiB}_{2} / \mathrm{Al}_{2} \mathrm{O}_{3}$ hybrid surface nanocomposite by friction stir processing. Procedia Mater. Sci. 2015, 11, 503-508. [CrossRef]

6. Karpasand, F.; Abbasi, A.; Ardestani, M. Effect of amount of $\mathrm{TiB}_{2}$ and $\mathrm{B}_{4} \mathrm{C}$ particles on tribological behavior of $\mathrm{Al}_{7075} / \mathrm{B}_{4} \mathrm{C} / \mathrm{TiB}_{2}$ mono and hybrid surface composites produced by friction stir processing. Surf. Coat. Technol. 2020, 390, 125680. [CrossRef]

7. Mazahery, A.; Ostadshabani, M. Investigation on mechanical properties of nano- $\mathrm{Al}_{2} \mathrm{O}_{3}$-reinforced aluminum matrix composites. J. Compos. Mater. 2011, 45, 2579-2586. [CrossRef]

8. Moustafa, E.B.; Melaibari, A.; Basha, M. Wear and microhardness behaviors of AA7075/SiC-BN hybrid nanocomposite surfaces fabricated by friction stir processing. Ceram. Int. 2020, 46, 16938-16943. [CrossRef] 
9. Ostovan, F.; Amanollah, S.; Toozandehjani, M.; Shafiei, E. Fabrication of Al5083 surface hybrid nanocomposite reinforced by $\mathrm{CNTs}$ and $\mathrm{Al}_{2} \mathrm{O}_{3}$ nanoparticles using friction stir processing. J. Compos. Mater. 2019, 54, 1107-1117. [CrossRef]

10. Rana, H.G.; Badheka, V.J.; Kumar, A. Fabrication of Al7075/ $\mathrm{B}_{4} \mathrm{C}$ surface composite by novel friction stir processing (FSP) and investigation on wear properties. Procedia Technol. 2016, 23, 519-528. [CrossRef]

11. Umanath, K.; Selvamani, S.T.; Palanikumar, K.; Sabarikreeshwaran, R. Dry Sliding wear behaviour of AA6061-T6 reinforced SiC and $\mathrm{Al}_{2} \mathrm{O}_{3}$ particulate hybrid composites. Procedia Eng. 2014, 97, 694-702. [CrossRef]

12. Abushanab, W.S.; Moustafa, E.B.; Melaibari, A.A.; Kotov, A.D.; Mosleh, A.O. A novel comparative study based on the economic feasibility of the ceramic nanoparticles role's in improving the properties of the AA5250 nanocomposites. Coatings 2021, 11, 977. [CrossRef]

13. Aruri, D.; Adepu, K.; Adepu, K.; Bazavada, K. Wear and mechanical properties of 6061-T6 aluminum alloy surface hybrid composites $\left[(\mathrm{SiC}+\mathrm{Gr})\right.$ and $\left.\left(\mathrm{SiC}+\mathrm{Al}_{2} \mathrm{O}_{3}\right)\right]$ fabricated by friction stir processing. J. Mater. Res. Technol. 2013, 2, 362-369. [CrossRef]

14. Chao, W.; Xiangxin, X.; Xiaozhou, C.; He, Y.; Gongjin, C. The Effect of Ti addition on the microstructure and fracture toughness of Bn-Al composite materials synthesized by vacuum infiltration. Arch. Metall. Mater. 2013, 58, 509-512. [CrossRef]

15. Xiaozhou, C.; Chao, W.; Xiangxin, X.; Gongjin, C. Effect of Ti addition on the residual aluminium content and mechanical Properties of the $\mathrm{B}_{4} \mathrm{C}-\mathrm{Al}$ composites produced by vacuum infiltration/wpływ dodatku tytanu Na resztkowa zawartość aluminium I właściwości mechaniczne kompozytów $\mathrm{B}_{4} \mathrm{C}-\mathrm{Al}$ wytworzonych przez infiltracje próżniową. Arch. Metall. Mater. 2015, 60, 2493-2498. [CrossRef]

16. Bauri, R.; Ram, G.D.J.; Yadav, D.; Kumar, C.N.S. Effect of process parameters and tool geometry on fabrication of Ni particles reinforced $5083 \mathrm{Al}$ composite by friction stir processing. Mater. Today Proc. 2015, 2, 3203-3211. [CrossRef]

17. Du, Z.; Tan, M.J.; Guo, J.F.; Bi, G.; Wei, J. Fabrication of a new $\mathrm{Al}-\mathrm{Al}_{2} \mathrm{O}_{3}-\mathrm{CNTs}$ composite using friction stir processing (FSP). Mater. Sci. Eng. A 2016, 667, 125-131. [CrossRef]

18. Mirjavadi, S.S.; Alipour, M.; Hamouda, A.M.S.; Matin, A.; Kord, S.; Afshari, B.M.; Koppad, P.G. Effect of multi-pass friction stir processing on the microstructure, mechanical and wear properties of AA5083/ $\mathrm{ZrO}_{2}$ nanocomposites. J. Alloys Compd. 2017, 726, 1262-1273. [CrossRef]

19. Paidar, M.; Ojo, O.O.; Ezatpour, H.R.; Heidarzadeh, A. Influence of multi-pass FSP on the microstructure, mechanical properties and tribological characterization of Al/B4C composite fabricated by accumulative roll bonding (ARB). Surf. Coat. Technol. 2019, 361, 159-169. [CrossRef]

20. Ding, Z.; Li, Z.; Li, H.; Chen, Y. Microstructure of Mg solid solution layer during multi-pass FSP of Mg/Al Composite Plates. Vacuum 2020, 172, 109078. [CrossRef]

21. Moharrami, A.; Razaghian, A.; Paidar, M.; Šlapáková, M.; Ojo, O.O.; Taghiabadi, R. Enhancing the mechanical and tribological properties of $\mathrm{Mg}_{2} \mathrm{Si}$-rich aluminum alloys by multi-pass friction stir processing. Mater. Chem. Phys. 2020, 250, 123066. [CrossRef]

22. Moustafa, E.; Mohammed, S.; Wanis, S.; Mahmoud, T.; El-Kady, E. Effect of friction stir processing parameters on the tensile strength of surface composite aluminum alloy. Int. J. Adv. Res. 2016, 5, 2061-2065. [CrossRef]

23. Moustafa, E. Effect of Multi-Pass friction stir processing on mechanical properties for $\mathrm{AA} 2024 / \mathrm{Al}_{2} \mathrm{O}_{3}$ nanocomposites. Materials 2017, 10, 1053. [CrossRef]

24. Abdel Aziz, S.S.; Abulkhair, H.; Moustafa, E.B. Role of hybrid nanoparticles on thermal, electrical conductivity, microstructure, and hardness behavior of nanocomposite matrix. J. Mater. Res. Technol. 2021, 13, 1275-1284. [CrossRef]

25. Essam, B.; Moustafa, S.M.; Wanis, S.; Mahmoud, T. Surface composite defects of $\mathrm{Al}-\mathrm{Al}_{2} \mathrm{O}_{3}$ metal matrix. J. Mater. Sci. Surf. Eng. 2017, 5, 524-527. [CrossRef]

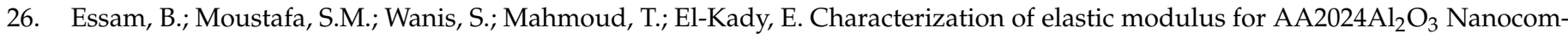
posite beam obtained from dynamic and static methods. Int. J. Res. Dev. Technol. 2016, 6, 124-128.

27. Yang, $\mathrm{K}$; $\mathrm{Li}, \mathrm{W}$.; Xu, Y.; Yang, X. Using friction stir processing to augment corrosion resistance of cold sprayed $\mathrm{AA}_{2024} / \mathrm{Al}_{2} \mathrm{O}_{3}$ composite coatings. J. Alloys Compd. 2019, 774, 1223-1232. [CrossRef]

28. Bourkhani, R.D.; Eivani, A.R.; Nateghi, H.R. Through-thickness inhomogeneity in microstructure and tensile properties and tribological performance of friction stir processed $\mathrm{AA} 1050-\mathrm{Al}_{2} \mathrm{O}_{3}$ nanocomposite. Compos. Part B Eng. 2019, $174,107061$. [CrossRef]

29. Yang, K.; Li, W.; Huang, C.; Yang, X.; Xu, Y. Optimization of cold-sprayed AA2024/ $\mathrm{Al}_{2} \mathrm{O}_{3}$ metal matrix composites via friction stir processing: Effect of rotation speeds. J. Mater. Sci. Technol. 2018, 34, 2167-2177. [CrossRef]

30. Raaft, M.; Mahmoud, T.S.; Zakaria, H.M.; Khalifa, T.A. Microstructural, mechanical and wear behavior of A390/graphite and A390/ $\mathrm{Al}_{2} \mathrm{O}_{3}$ surface composites fabricated using FSP. Mater. Sci. Eng. A 2011, 528, 5741-5746. [CrossRef]

31. Murugan, S.; Ahmed, T. Multiple response optimization of friction stir processing aluminium alloy using response surface methodology and grey relation. In Proceedings of the 2019 8th International Conference on Modeling Simulation and Applied Optimization (ICMSAO), Manama, Bahrain, 15-17 April 2019; pp. 1-5.

32. Chanakyan, C.; Sivasankar, S.; Meignanamoorthy, M.; Ravichandran, M.; Muralidharan, T. Experimental investigation on influence of process parameter on friction stir processing of AA6082 using response surface methodology. Mater. Today Proc. 2020, 21, 231-236. [CrossRef]

33. Venkateswarlu, G.; Davidson, M.J.; Tagore, G.R.N. Analysis of sheet metal formability studies of friction stir processed Mg AZ31B alloy using response surface methodology. Procedia Eng. 2012, 38, 2228-2236. [CrossRef] 
34. Shehabeldeen, T.A.; Elaziz, M.A.; Elsheikh, A.H.; Zhou, J. Modeling of friction stir welding process using adaptive neuro-fuzzy inference system integrated with harris hawks optimizer. J. Mater. Res. Technol. 2019, 8, 5882-5892. [CrossRef]

35. Shehabeldeen, T.A.; Elaziz, M.A.; Elsheikh, A.H.; Hassan, O.F.; Yin, Y.; Ji, X.; Shen, X.; Zhou, J. A novel method for predicting tensile strength of friction stir welded AA6061 aluminium alloy joints based on hybrid random vector functional link and henry gas solubility optimization. IEEE Access 2020, 8, 79896-79907. [CrossRef]

36. Abd Elaziz, M.; Shehabeldeen, T.A.; Elsheikh, A.H.; Zhou, J.; Ewees, A.A.; Al-qaness, M.A.A. Utilization of random vector functional link integrated with marine predators algorithm for tensile behavior prediction of dissimilar friction stir welded aluminum alloy joints. J. Mater. Res. Technol. 2020, 9, 11370-11381. [CrossRef]

37. AbuShanab, W.S.; Abd Elaziz, M.; Ghandourah, E.I.; Moustafa, E.B.; Elsheikh, A.H. A new fine-tuned random vector functional link model using Hunger games search optimizer for modeling friction stir welding process of polymeric materials. J. Mater. Res. Technol. 2021, 14, 1482-1493. [CrossRef]

38. Elsheikh, A.H.; Katekar, V.P.; Muskens, O.L.; Deshmukh, S.S.; Elaziz, M.A.; Dabour, S.M. Utilization of LSTM neural network for water production forecasting of a stepped solar still with a corrugated absorber plate. Process. Saf. Environ. Prot. 2021, 148, 273-282. [CrossRef]

39. Elsheikh, A.H.; Shehabeldeen, T.A.; Zhou, J.; Showaib, E.; Abd Elaziz, M. Prediction of laser cutting parameters for polymethylmethacrylate sheets using random vector functional link network integrated with equilibrium optimizer. J. Intell. Manuf. 2021, 32, 1377-1388. [CrossRef]

40. Essa, F.A.; Abd Elaziz, M.; Elsheikh, A.H. An enhanced productivity prediction model of active solar still using artificial neural network and Harris Hawks optimizer. Appl. Therm. Eng. 2020, 170, 115020. [CrossRef]

41. Babikir, H.A.; Elaziz, M.A.; Elsheikh, A.H.; Showaib, E.A.; Elhadary, M.; Wu, D.; Liu, Y. Noise prediction of axial piston pump based on different valve materials using a modified artificial neural network model. Alex. Eng. J. 2019, 58, 1077-1087. [CrossRef]

42. Khoshaim, A.B.; Elsheikh, A.H.; Moustafa, E.B.; Basha, M.; Mosleh, A.O. Prediction of residual stresses in turning of pure iron using artificial intelligence-based methods. J. Mater. Res. Technol. 2021, 11, 2181-2194. [CrossRef]

43. Elaziz, M.A.; Elsheikh, A.H.; Sharshir, S.W. Improved prediction of oscillatory heat transfer coefficient for a thermoacoustic heat exchanger using modified adaptive neuro-fuzzy inference system. Int. J. Refrig. 2019, 102, 47-54. [CrossRef]

44. Abd Elaziz, M.; Senthilraja, S.; Zayed, M.E.; Elsheikh, A.H.; Mostafa, R.R.; Lu, S. A new random vector functional link integrated with mayfly optimization algorithm for performance prediction of solar photovoltaic thermal collector combined with electrolytic hydrogen production system. Appl. Therm. Eng. 2021, 193, 117055. [CrossRef]

45. Essa, F.A.; Abd Elaziz, M.; Elsheikh, A.H. Prediction of power consumption and water productivity of seawater greenhouse system using random vector functional link network integrated with artificial ecosystem-based optimization. Process Saf. Environ. Prot. 2020, 144, 322-329. [CrossRef]

46. Elmaadawy, K.; Elaziz, M.A.; Elsheikh, A.H.; Moawad, A.; Liu, B.; Lu, S. Utilization of random vector functional link integrated with manta ray foraging optimization for effluent prediction of wastewater treatment plant. J. Environ. Manag. 2021, 298, 113520. [CrossRef]

47. Elsheikh, A.H.; Abd Elaziz, M.; Ramesh, B.; Egiza, M.; Al-Qaness, M.A.A. Modeling of drilling process of GFRP composite using a hybrid random vector functional link network/parasitism-predation algorithm. J. Mater. Res. Technol. 2021, 14, $298-311$. [CrossRef]

48. Elsheikh, A.H.; Elaziz, M.A.; Das, S.R.; Muthuramalingam, T.; Lu, S. A new optimized predictive model based on political optimizer for eco-friendly MQL-turning of AISI 4340 alloy with nano-lubricants. J. Manuf. Process. 2021, 67, 562-578. [CrossRef]

49. Elsheikh, A.H.; Guo, J.; Huang, Y.; Ji, J.; Lee, K.-M. Temperature field sensing of a thin-wall component during machining: Numerical and experimental investigations. Int. J. Heat Mass Transf. 2018, 126, 935-945. [CrossRef]

50. Salman, K.H.; Elsheikh, A.H.; Ashham, M.; Ali, M.K.A.; Rashad, M.; Haiou, Z. Effect of cutting parameters on surface residual stresses in dry turning of AISI 1035 alloy. J. Braz. Soc. Mech. Sci. Eng. 2019, 41, 349. [CrossRef]

51. Santhosh Kumar, K.; Vaira Vignesh, R.; Ajith Kumar, G.; Abiram, A.; Padmanaban, R. Soft computing model for predicting the wear resistance of friction stir processed aluminum alloy AA5083. Mater. Today Proc. 2021, 46, 7236-7243. [CrossRef]

52. Rathore, S.; Raj Singh, R.K.; Khan, K.L.A. Artificial intelligent approach for process parameters modeling of friction stir processing. Mater. Today Proc. 2021, 43, 326-334. [CrossRef]

53. Dinaharan, I.; Palanivel, R.; Murugan, N.; Laubscher, R.F. Application of artificial neural network in predicting the wear rate of copper surface composites produced using friction stir processing. Aust. J. Mech. Eng. 2020, 1-12. [CrossRef]

54. Tyagi, L.; Butola, R.; Kem, L.; Singari, R.M. Comparative Analysis of response surface methodology and artificial neural network on the wear properties of surface composite fabricated by friction stir processing. J. Bio- Tribo-Corros. 2021, 7, 36. [CrossRef]

55. Moustafa, E.B.; AbuShanab, W.S.; Ghandourah, E.; Taha, M.A. Microstructural, mechanical and thermal properties evaluation of AA6061/ $\mathrm{Al}_{2} \mathrm{O}_{3}-\mathrm{BN}$ hybrid and mono nanocomposite surface. J. Mater. Res. Technol. 2020, 9, 15486-15495. [CrossRef]

56. Stoffel, M.; Bamer, F.; Markert, B. Artificial neural networks and intelligent finite elements in non-linear structural mechanics. Thin Walled Struct. 2018, 131, 102-106. [CrossRef]

57. Elsheikh, A.H.; Sharshir, S.W.; Abd Elaziz, M.; Kabeel, A.; Guilan, W.; Haiou, Z. Modeling of solar energy systems using artificial neural network: A comprehensive review. Sol. Energy 2019, 180, 622-639. [CrossRef]

58. Mirjalili, S.; Mirjalili, S.M.; Lewis, A. Grey wolf optimizer. Adv. Eng. Softw. 2014, 69, 46-61. [CrossRef] 